LA WRENCE LIWEAMCAE NATIONAL LABDAATOAY

A Microbeam Bending Method for Studying StressStrain Relations for Metal Thin Films on Silicon Substrates

J.N. Florando and W.D. Nix

February 17, 2004

Journal of the Mechanics and Physics of Solids 
This document was prepared as an account of work sponsored by an agency of the United States Government. Neither the United States Government nor the University of California nor any of their employees, makes any warranty, express or implied, or assumes any legal liability or responsibility for the accuracy, completeness, or usefulness of any information, apparatus, product, or process disclosed, or represents that its use would not infringe privately owned rights. Reference herein to any specific commercial product, process, or service by trade name, trademark, manufacturer, or otherwise, does not necessarily constitute or imply its endorsement, recommendation, or favoring by the United States Government or the University of California. The views and opinions of authors expressed herein do not necessarily state or reflect those of the United States Government or the University of California, and shall not be used for advertising or product endorsement purposes. 


\title{
A Microbeam Bending Method for Studying Stress-Strain Relations for Metal Thin Films on Silicon Substrates
}

\author{
J.N. Florando* and W.D. Nix ${ }^{* *}$ \\ Department of Materials Science and Engineering, \\ Stanford University, Stanford, CA 94305 \\ *Currently at Lawrence Livermore National Laboratory, 7000 East Ave. M/S L-527, \\ Livermore, CA 94550. \\ ${ }^{* *}$ Corresponding Author, Phone: 650-725-2605, Fax: 650-725-4034 \\ Email: nix@Stanford.edu
}

\begin{abstract}
We have developed a microbeam bending technique for determining elastic-plastic, stress-strain relations for thin metal films on silicon substrates. The method is similar to previous microbeam bending techniques, except that triangular silicon microbeams are used in place of rectangular beams. The triangular beam has the advantage that the entire film on the top surface of the beam is subjected to a uniform state of plane strain as the beam is deflected, unlike the standard rectangular geometry where the bending is concentrated at the support. We present a method of analysis for determining two Ramberg-Osgood parameters for describing the stress-strain relation for the film. These parameters are obtained by fitting the elastic-plastic model to the measured loaddisplacement data, and utilizing the known elastic properties of both film and substrate. As a part of the analysis we compute the position of the neutral plane for bending, which changes as the film deforms plastically. This knowledge, in turn, allows average stressstrain relations to be determined accurately without forcing the film to closely follow the Ramberg-Osgood law. The method we have developed can be used to determine the elastic-plastic properties of thin metal films on silicon substrates up to strains of about $1 \%$.
\end{abstract}


Utilizing this technique, both yielding and strain hardening of $\mathrm{Cu}$ thin films on silicon substrates have been investigated. Copper films with dual crystallographic textures and different grain sizes, as well as others with strong $<111>$ textures have been studied. Three strongly textured $<111>$ films were studied to examine the effect of film thickness on the deformation properties of the film. These films show very high rates of work hardening, and an increase in the yield stress and work hardening rate with decreasing film thickness, consistent with current dislocation models.

Author Keywords: thin films, plasticity, small-scale yielding, strain hardening, MEMS

\section{Introduction}

The expanding field of Micro-Electrical Mechanical Systems (MEMS) has led to the development of many useful engineering devices (Garcia and Sniegowski, 1995; DiLella, Whitman et al., 2000; Spearing, 2000). The decreasing dimensions of these devices require the development of new test methods for monitoring the mechanical reliability of these systems. Many different kinds of tests are available for studying the mechanical properties of materials in small dimensions (Nix, 1989); however, there is still need to develop simple test methods for measuring the isothermal stress-strain relations for thin films still attached to their substrates.

In an effort to devise a simple method for studying the elastic and plastic properties of thin films on substrates, a microbeam bending technique has been developed. The method is similar to previous work done on microbeam bending (Weihs, Hong et al., 1988; Baker and Nix, 1994), except that triangular silicon microbeams are used. The triangular beam has the advantage that the entire film on the top surface of the beam is subjected to a uniform state of strain as the beam is deflected, unlike the standard rectangular geometry where the bending is concentrated at the support.

We have fabricated rectangular and triangular silicon beams using micromachining and semiconductor processing techniques. Copper films are deposited on top of the $\mathrm{Si}$ beams, and the bi-layer beams are deflected using a nanoindenter. The sample geometry 
coupled with the high resolution of the nanoindenter allows this technique to have high strain resolution.

Typically, the onset of yielding is determined by the first deviation from linearity on the load-displacement curves; however, due to the relatively thick elastic Si substrate, the deviation in the load-displacement behavior is very gradual and small in magnitude. To extract the stress-strain behavior of the film from the load-displacement relation, a simple numerical model has been developed. The yielding behavior of the film can be modeled using a Ramberg-Osgood constitutive law for the film, which is then used to predict the stress-strain relation for the film while attached to its elastic substrate. This model has also been used to show that although there is a gradient of stress and strain through the thickness of the film during bending, this effect does not obscure the measurement of the yield stress of the film.

Utilizing this technique, the yielding and strain hardening behavior of bare $\mathrm{Cu}$ thin films have been investigated. A Cu film was thermally cycled from room temperature to $500^{\circ} \mathrm{C}$, and the film was tested after each cycle. The thermal cycles were performed to examine the effect of thermal processing on the stress-strain behavior of the film.

$\mathrm{Cu}$ films with dual, $<100>/<111>$, textures, as well as others with strong $<111>$ textures have also been studied. Strongly textured $<111>$ films were deposited at three different film thicknesses to examine the effect of texture, as well as film thickness, on the yield properties of the film. The $<111>$ textured films show very high rates of work hardening, an effect that has been predicted by recent modeling of thin film plasticity.

\section{Theory}

The advantage of the triangular beam is the constant moment per unit width acting in the beam during deflection. The idea for using triangular beams was independently suggested to the authors by Joost Vlassak and Qing Ma in the late 1990's. As shown in Fig. 1, the bending moment at any point along the beam is the product of the load, $P$ and the lever arm, $L-x$. Using similar triangles, the moment per unit width at any point in the beam can be expressed as: 


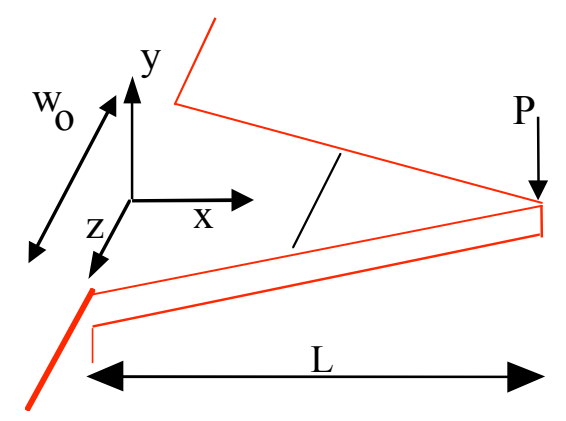

Figure 1 - Top view schematic of triangular beam.

$$
M=\frac{M_{t}}{w}=\frac{P(L \square x)}{w}=\frac{P(L \square x)}{w_{o} \frac{\square \square x \square}{L}=\frac{P L}{w_{o}}}=\text { constant }
$$

Thus the triangular beam is subjected to a constant moment (per unit width) and the beam naturally develops a uniform curvature. As a consequence, the entire film on the top surface of the beam is subjected to a uniform state of plane strain and the film can be expected to yield simultaneously at all points along the beam, unlike the standard rectangular geometry where yielding first occurs at the support. In what follows we assume that a bi-layer triangular beam consisting of a metal film of uniform thickness on top of an elastic beam of uniform thickness is deflected at its end with a force $P$ resulting in a displacement $u$. The response of the beam is assumed to be time independent so that any foreword running parameter, such as the load point deflection, can serve as time. The incremental load point deflection, $\square$, may then be regarded as a time derivative for a time-independent process. Corresponding increments in the load, $\square P$, moment (per unit width $), \square M=\left(L / w_{o}\right) \square P$, and curvature, $\square=\left(2 / L^{2}\right) \square u$, similarly represent time derivatives for this time-independent bending process. Using the uniform strain state for the triangular geometry, the stress-strain properties of the film can be extracted using the analyses described below. 


\subsection{Elastic-Plastic Analysis}

We consider the deflection of a triangular microbeam of thickness $t_{s}$ with a metal film of thickness $t_{f}$ bonded to the top surface of the beam. The length of the beam is $L$ and the width of the beam at its base is $w_{o}$. For a film on an elastic substrate with known elastic properties, the deformation properties of the film can be extracted from the bending response of the bi-layer beam. Silicon, which behaves in a linear elastic manner in these experiments, is used as the substrate material, so yielding is limited to the metal film. We first model the deformation behavior of the film using the empirical RambergOsgood stress-strain law,

$$
\square^{f}=\frac{\square^{f}}{E_{f}}+\frac{\square_{o}}{E_{f}} \stackrel{\square}{\square} \stackrel{\square^{f}}{\square_{o}} \stackrel{\mid}{\square}
$$

where $\pi^{f}$ is the equivalent strain, $\Pi^{f}$ is the equivalent stress, $E_{f}$ is Young's modulus, $\square_{o}$ is the uniaxial yield stress, and $1 / m$ is a strain hardening exponent. This model, in conjunction with elastic deformation of the substrate, can be used to extract the properties of the film $\left(\square_{o}\right.$ and $\left.m\right)$ from the experimental load-displacement data. To make this determination we first assume values for $\square_{o}$ and $m$ and calculate the incremental loads and displacements during bending. We choose those values of $\square_{o}$ and $m$ that provide the best fit to the experimental load-displacement data. As shown in Appendix A, for a given set of $\square_{o}$ and $m$, the incremental bending loads can be related to the incremental bending displacements using

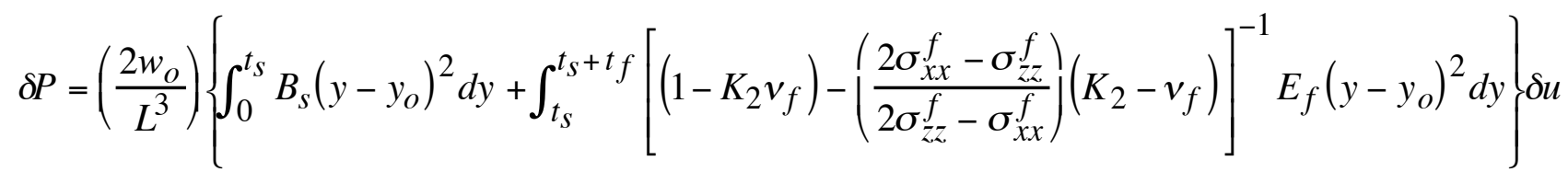

where $B_{S}$ is the plane strain modulus of the substrate and where the in-plane stresses in the film, $\square_{x x}^{f}$ and $\square_{z z}^{f}$, are found for each increment of bending using 


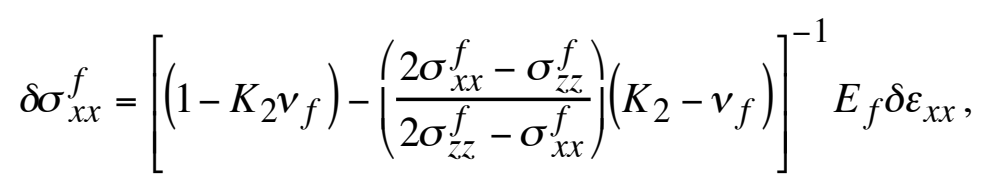

and

$$
\square_{z z}^{f}=K_{2} \square_{x x}^{f},
$$

with the strain increment $\square_{x x}$ given by

$$
\square_{x x}(y)=\square\left(y \square y_{o}\right),
$$

where $\square=\left(2 / L^{2}\right) \square u$.

The parameter $K_{2}$ in these relations is found using

$$
K_{2}=\frac{\left(\square_{f} \square^{f} \square K_{1}\left(2 \square_{x x}^{f} \square \square_{z z}^{f}\right)\right)}{\left(\square^{f}+K_{1}\left(2 \square_{z z}^{f} \square \square_{x x}^{f}\right)\right)}
$$

where

$$
K_{1}=\frac{m}{2} \frac{\prod_{z z}^{f} \square \frac{1}{2} \square_{x x}^{f} \square^{f}}{\square^{f} \square^{f} \square^{m \square 1}} .
$$

Finally, the position for the neutral plane for bending, $y_{o}$, must be computed after each increment of bending by solving

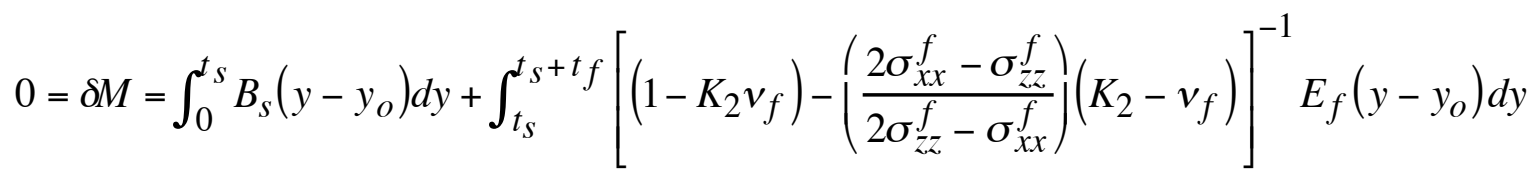

(9) 


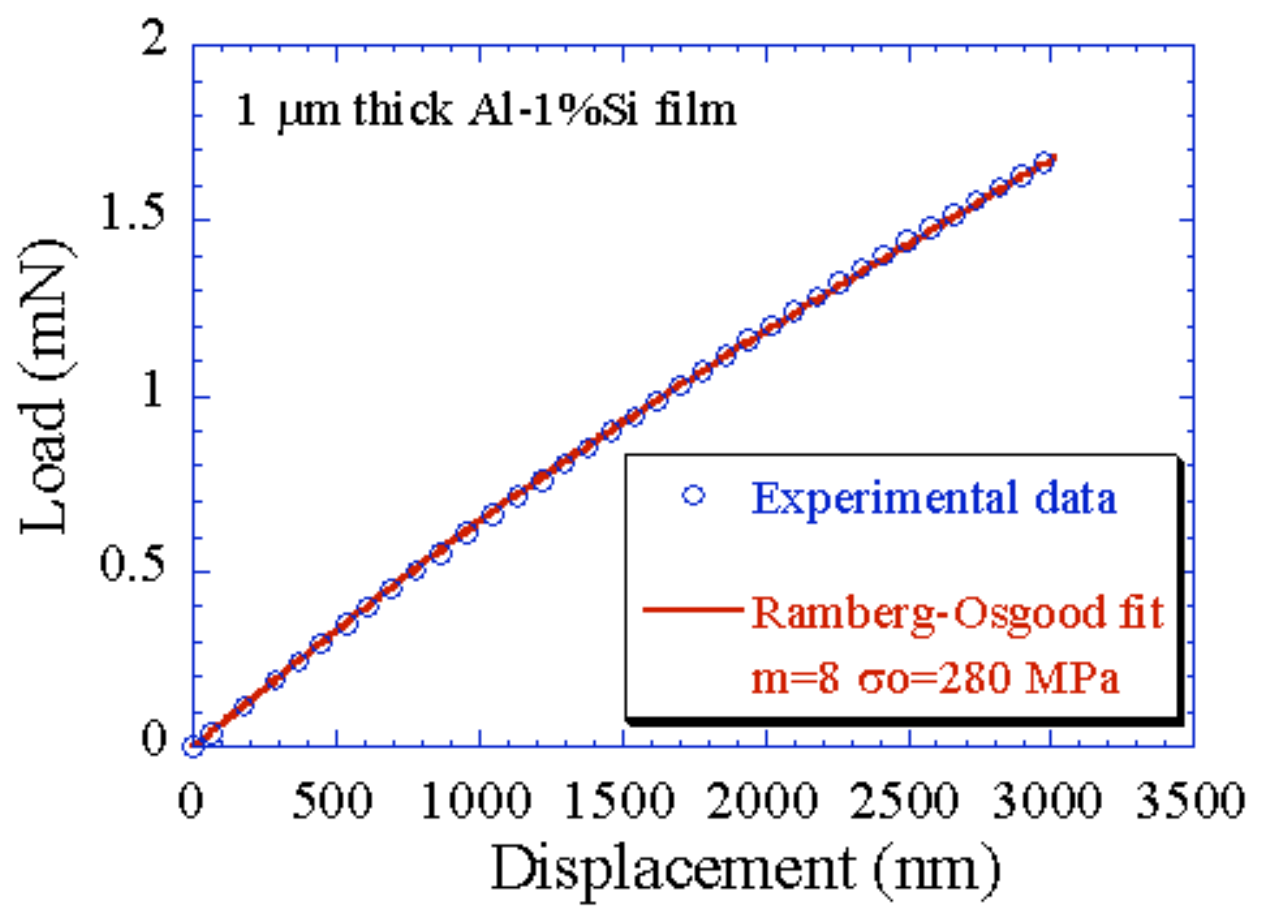

Figure 2 - Matching the Ramberg-Osgood model to the experimental load-displacement data for a $1 \square \mathrm{m}$ Al-1\%Si film on a Si substrate using a $\square$ o of $280 \mathrm{MPa}$, and an $\mathrm{m}$ of 8 .

Utilizing eqn.(3), a theoretical load-displacement curve can be calculated for a film that follows the Ramberg-Osgood law. By changing the yield stress $\square_{0}$, and the strain hardening exponent $1 / m$, the theoretical load-displacement curve can be fitted to match the experimental data. A match of the model to experimental data is shown in Fig. 2. The data used here is for a $1 \square \mathrm{m}$ thick Al-1\%Si film on a $4.2 \square \mathrm{m}$ thick Si beam. The model matches the data well using a yield stress of $280 \mathrm{MPa}$ and an $\mathrm{m}$ of 8 .

\subsection{Average Stress Model}

Although the Ramberg-Osgood model gives a good estimate of the yield stress and the work hardening exponent, it forces the film to behave in a Ramberg-Osgood manner. A more flexible description of the yielding behavior of the film can be found by using the following average stress and strain model. The average incremental stress in the film on a triangular beam can be expressed as 


$$
\square<\square>=\frac{L \square P_{f i l m}}{w_{o} \bigsqcup_{s}^{t^{+t} f}\left(y \square y_{o}\right) d y}=\frac{2 L \square P_{f i l m}}{w_{o} t_{f}\left\lfloor 2 t_{s}+t_{f} \square 2 y_{o}\right\rfloor},
$$

where $\left[P_{\text {film }}\right.$ is the incremental load associated with the film alone, and $y_{o}$ is the position of the neutral plane for bending. For the Ramberg-Osgood analysis described above, the neutral plane positions are continuously calculated as the film yields. Since this model is fitted to the experimental data, it can be used to provide very good estimates of the neutral plane positions during bending. Since the other quantities in eqn. (10), are experimentally determined, the Ramberg-Osgood analysis is here used only to estimate the position of the neutral plane for bending. It does not constrain the film to follow the Ramberg-Osgood law. The measured load, $\Gamma$, includes load contributions from the substrate. Thus $\left[P_{\text {film }}\right.$, needed for the implementation of eqn.(10), is found using,

$$
\square P_{\text {film }}=\square P \square \square P_{\text {substrate }}
$$

where $\left[P_{\text {substrate }}\right.$ is calculated from the elastic properties and dimensions of the substrate and knowledge of the current position of the neutral plane,

$$
\left[P_{\text {substrate }}=\frac{2 w_{0}}{L^{3}} B_{s} \square u \coprod^{s}\left(y \square y_{o}\right)^{2} d y=\frac{2 w_{0}}{L^{3}} B_{s}\left[t_{s}^{3} \square 3 t_{s}^{2} y_{o}+3 t_{s} y_{o}^{2}\right][u\right.
$$

The average incremental strain in the film can also be expressed as

$$
\square<\square_{x x}>=\frac{2 \square u}{t_{f} L^{2}} \rrbracket^{t+t f}\left(y \square y_{o}\right) d y=\frac{\square u}{L^{2}}\left[2 t_{s}+t_{f} \square 2 y_{o}\right] .
$$




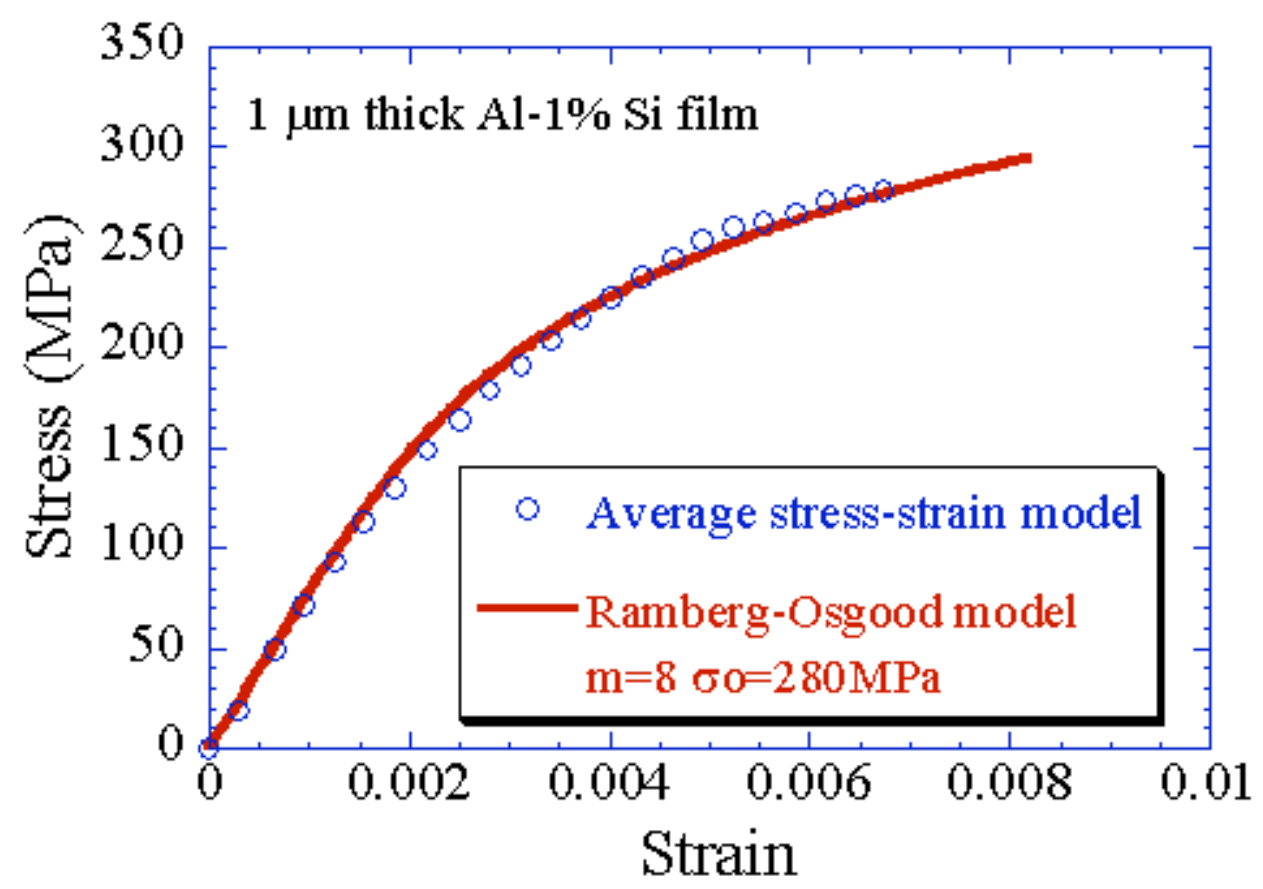

Figure 3 - Comparing the average stress and strain with the Ramberg-Osgood model. The $1 \square \mathrm{m}$ $\mathrm{Al}-1 \% \mathrm{Si}$ film is deposited on a $30^{\circ} 46 \square \mathrm{m}$ long triangular Si beam.

Thus, using eqns (10) and (13), the average stress and strain the film can be extracted directly from the beam bending experiment. These equations are mainly a function of the known geometry, and the experimental loads and displacements. The only unknowns are the neutral plane positions, which can be estimated using the Ramberg-Osgood analysis, as described above. Knowledge of the movement of the neutral plane position permits a calculation of the average stress and strain in the film. The average stress-strain relation obtained using this method is compared to the corresponding Ramberg-Osgood model in Fig. 3. While there is good overall agreement in these relations, justifying the use of the Ramberg-Osgood model, the average stress-strain relation is considered more accurate as it is not constrained to follow a particular form.

\subsection{Verifying the average stress-strain approximation}

The model for the average stress-strain relation assumes that there is no variation in stress through the thickness of the film, and treats the film as if it were subjected to a homogeneous stress state. However, in bending there is a linear variation in strain 
through the thickness of the film, with the highest strain occurring at the top of the film. Since the film will yield at the top of the film first and then through the thickness of the film, the average equations may be insensitive to sharp features in the stress-strain relation. For example, in the beam bending experiment the load-displacement data will be inherently gradual even if the film exhibits a sharp yield point. Since the average stress and strain in the film is extracted from this load-displacement data, the stress strain behavior of the film would be predicted to be gradual as well, even if the film's "real" stress strain behavior has a sharp yield point. Therefore the gradual yielding shown in

Fig. 3 could be an effect of the bending experiment and the calculated average stress and strain in the film. This potential error can be checked by assuming that the film behaves in a manner that will produce a very abrupt yield point, such as in the case of a film characterized by an elastic-linear strain hardening law. Assuming that the film behaves in this manner, a theoretical load-displacement relationship can be derived, using expressions similar to eqn. (3). The calculated loads and displacements are then treated as "data", and inserted into the average stress-strain equations to determine if the original linear-hardening law can be recovered. Figure 4 shows that the mean stress-strain equations can reproduce the original linear hardening curve quite well. Therefore, the approximation of treating the film as having a uniform stress state through the thickness of the film is valid. All stress-strain plots throughout he remainder of this paper use the average stress-strain equations to determine the stress-strain behavior of the film.

\section{Wafer Processing}

A silicon-on-insulator (SOI) wafer was used to create beams of uniform geometry. The dimensions of the SOI wafer include a $1 \square \mathrm{m}$ backseal thermal oxide layer, a $675 \square \mathrm{m}$ bottom Si layer, a 0.5 $\square \mathrm{m}$ middle oxide layer, and a 4-5 $\square \mathrm{m}$ top Si layer. The beam structures were patterned in the top layer using standard photolithography, and etched with dry plasma etching. The high selectivity of the plasma etch between silicon and $\mathrm{SiO}_{2}$ allows the middle oxide layer to be used as an etchstop. The etchstop allows the beams to be over-etched to produce straight sidewalls. Once the beams were patterned, an oxide layer was deposited on the beams to help protect it from later processing steps. 


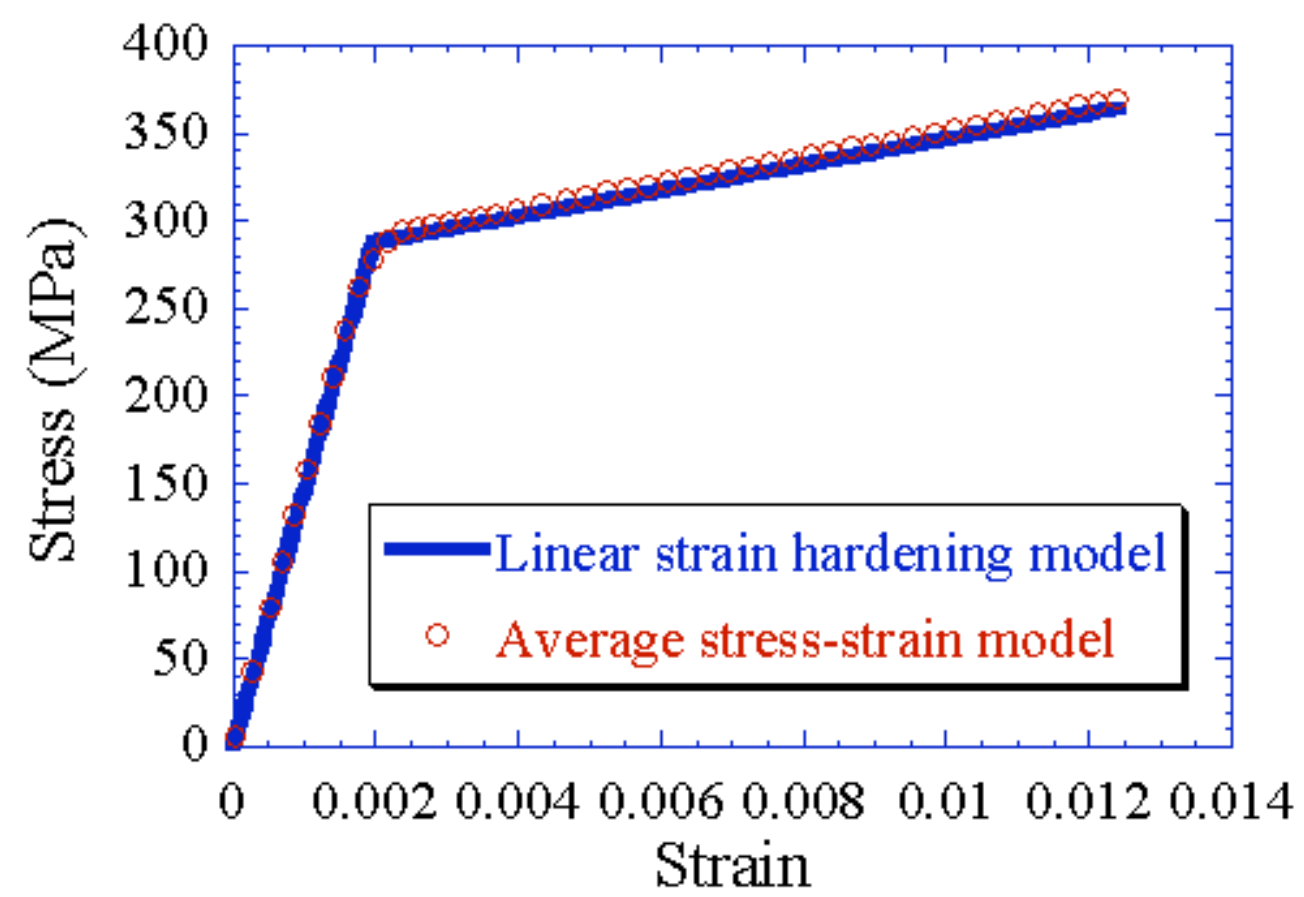

Figure 4 - Stress-Strain plots for a theoretical "film" that follows a linear hardening model, comparing the average stress-strain equations to the stress-strain law.

A nitride layer was then deposited on the backside of the wafer to act as an etch mask for the deep wet etching. In order to release the beams, an etch window was patterned into the back nitride and oxide layers using standard lithography techniques. A resist layer 7 $\square \mathrm{m}$ thick was used to ensure that the dimensions and shape of the etch window were maintained in the nitride and oxide layers during the plasma etch. The resist was then patterned using a Karlsuss MA-6 Back Aligner, which aligns the back etch window to the front beams. The Karlsuss has a maximum resolution of $0.75 \square \mathrm{m}$ in high magnification mode. After the etch window was patterned into the resist, the nitride and oxide layers were etched with a dry plasma etcher.

After the window is etched into the nitride and oxide layers, the wafer is placed in a one-side etcher to protect the front side (Holhlfelder, 1998). The etcher is filled with a $25 \%$ tetramethyl ammonium hydroxide (TMAH) solution, and placed in a heated water bath at $80^{\circ} \mathrm{C}$. TMAH etches silicon anisotropically and produces a trench that is bounded by (111) planes. The etch rate for silicon in TMAH is about $25 \square \mathrm{m} / \mathrm{min}$ at $80^{\circ} \mathrm{C}$, and 

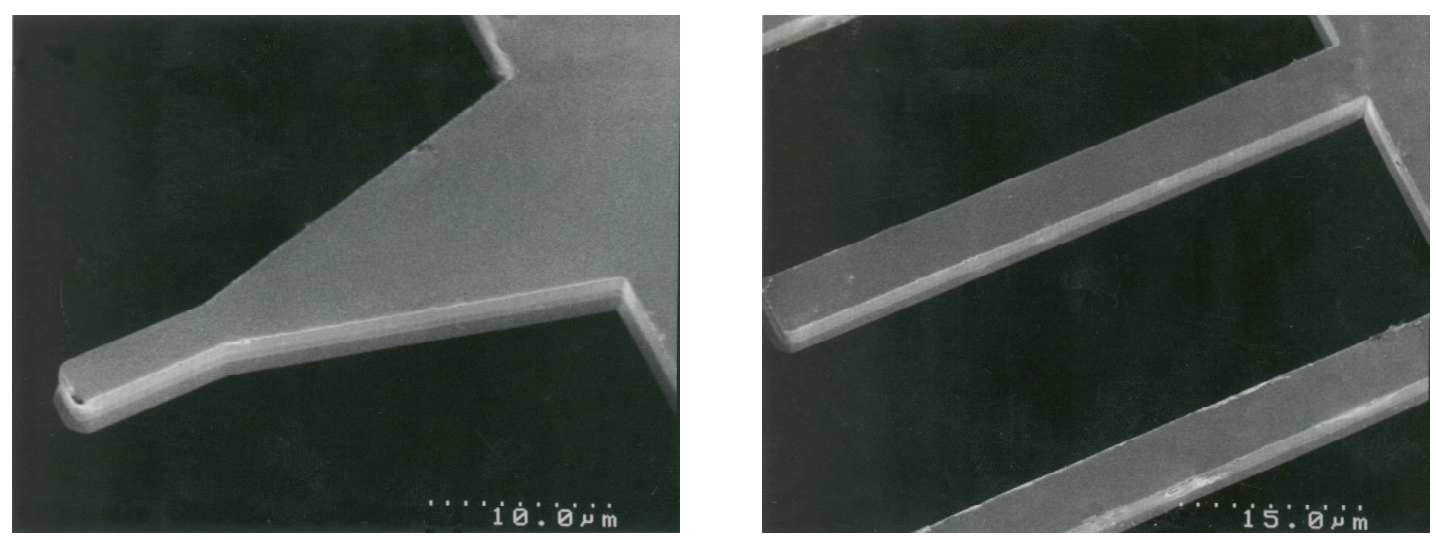

Figure 5 - SEM photograph of Si microbeams.

TMAH has a high selectivity with respect to the oxide ( 2000:1), so the middle oxide layer is again used as an etchstop. Once the bottom Si wafer is etched, after about 30 hours, the wafer is placed in a bath of 6:1 buffered oxide etch (an HF solution), which etches off the top and middle oxide layers to form free standing Si microbeams (Fig. 5). The film is then deposited on the beams to produce the bi-layer structure.

On one set of beams, $500 \AA$ of thermal oxide was first grown on the Si microbeams. A Cu film, $1 \square \mathrm{m}$ in thickness, was then deposited on top of the thermal oxide at room temperature, with a base pressure of $5 \times 10^{-6}$ torr, an Ar pressure of $2 \mathrm{mtorr}, 470 \mathrm{~V}, 0.4$ A., and $190 \mathrm{~W}$ of power. For three other sets of beams, $500 \AA$ of Tantalum was first deposited on the Si microbeams, for the purpose of controlling the texture of the subsequently deposited $\mathrm{Cu}$ films. The wafers were first cleaned with acetone, methanol, and ethanol, and then baked at $100^{\circ} \mathrm{C}$ for 30 min under vacuum to dry off moisture and organics. Tantalum was deposited at $100{ }^{\circ} \mathrm{C}$ with a base pressure of $10^{-8}$ torr, an $\mathrm{Ar}$ pressure of 3 mtorr, $280 \mathrm{~V}, 0.04 \mathrm{~A}$ and $10 \mathrm{~W}$ of power. Without breaking vacuum, copper was then deposited on top of the Ta at $250{ }^{\circ} \mathrm{C}$ with a base pressure of $10^{-8}$ torr, an $\mathrm{Ar}$ pressure of 3 mtorr, $363 \mathrm{~V}, 0.025 \mathrm{~A}$, and $25 \mathrm{~W}$ of power. Films of three different thicknesses: $0.5 \square \mathrm{m}, 1.0 \square \mathrm{m}$, and $1.7 \square \mathrm{m}$, were sputtered onto separate sets of beams.

\section{Description of testing method}

The microbeams were deflected using the Nano II nanoindenter from the MTS Nano Innovation Center. This particular instrument has a load resolution of $10 \mathrm{nN}$, and a 
displacement resolution of $0.3 \mathrm{~nm}$, which allows the microbeam bending technique to have a strain resolution on the order of 0.1 microstrain. Instead of using the traditional point load, a line load was applied to the beams using a diamond wedge tip that is $10 \square \mathrm{m}$ long and has a $90^{\circ}$-included angle. The line load was used to reduce the torsional bending of the beam.

As seen in Fig. 5, the triangular beams have a rectangular pad at the end to provide a location for the nanoindenter to bend the beam. This pad makes the beam stiffer than the ideal triangular geometry. An analysis performed to account for this effect (Florando, 2003) shows that by using sufficiently long beams (60 $\square \mathrm{m}$ or longer), the results converge to the ideal triangular geometry. The triangular beams used in this paper are longer than $60 \square \mathrm{m}$ and were approximated as beams with an ideal triangular geometry.

The beams were loaded at a constant displacement rate, which is equivalent to a constant strain rate, held for 100 seconds at the maximum load, and then unloaded at the same displacement rate as the loading segment. All the beam tests were performed at a strain rate on the order of $10^{-5} / \mathrm{sec}$.

Since a sharp indenter tip is used to deflect the beams, the tip makes an impression in the surface of the film as the beam is deflected. The indentation displacements can be removed by assuming that for a given load the indentation displacement into the film will be the same as the displacement in the film where it is well-supported by the substrate. This indentation response is then subtracted from the experimental displacement data to obtain the displacement of the beam. The compliance of the support also adds additional displacements to the end of the beam that must be taken into account. The support compliance is calculated using the measured support compliances for rectangular beams (Baker and Nix, 1994; Florando, Fujimoto et al., 1999) and the assumption that the support compliance varies linearly with the width of the base of the beam. Knowledge of the support compliance, the length of the beam, and the load, allows for the displacements at the end of the beam due to the support compliance to be calculated. These calculated displacements are then subtracted from the experimental data to obtain the beam displacements due to bending. 


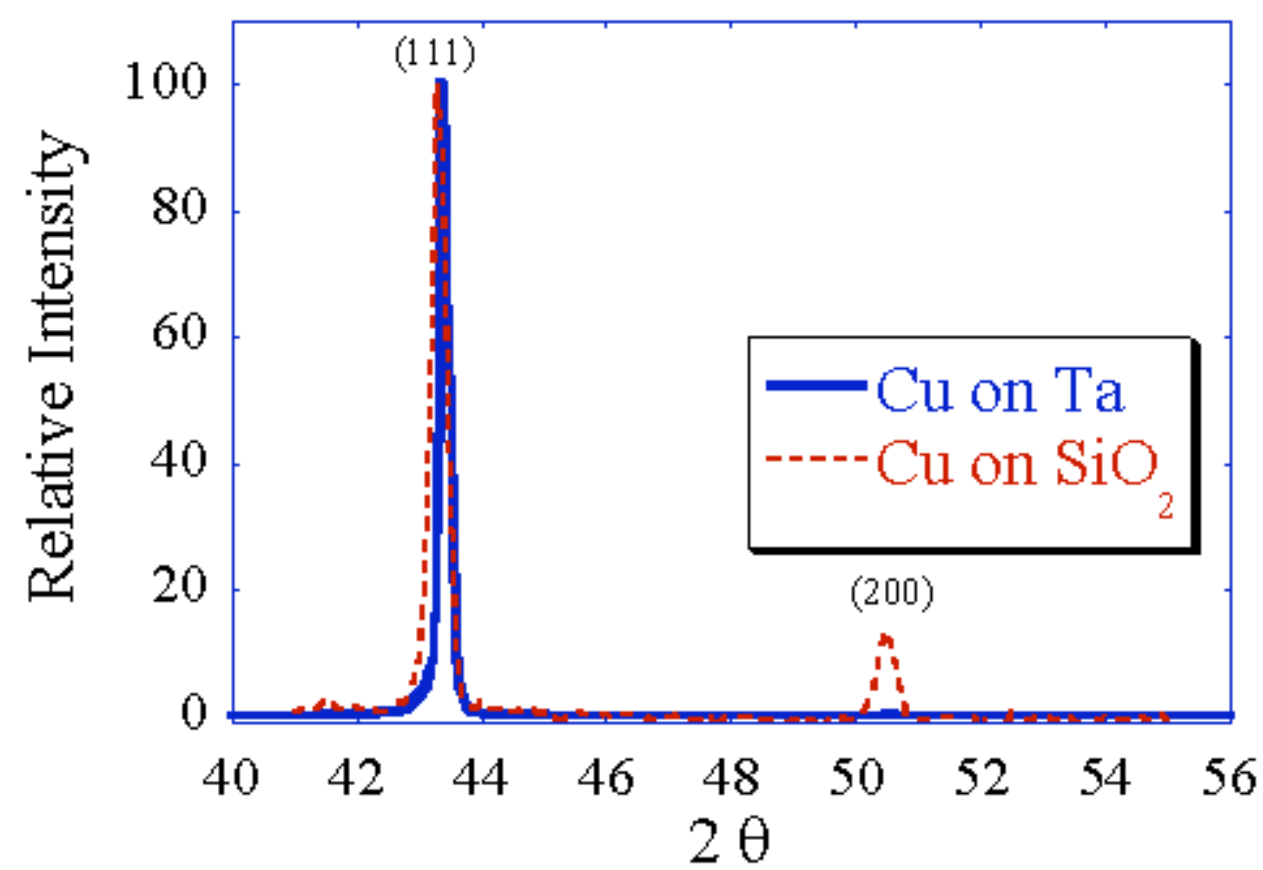

Figure 6 - Symmetric x-ray diffraction scans for a $\mathrm{Cu}$ film deposited on $\mathrm{SiO} 2$ (dashed) and $\mathrm{Ta}$ (solid line) showing a dual $<111>\mid<200>$ texture for the film grown on $\mathrm{SiO} 2$ and a strong $<111>$ texture for the film grown on Ta.

\section{Film Characterization}

The grain sizes for the $\mathrm{Cu}$ films grown on $\mathrm{SiO}_{2}$ and $\mathrm{Ta}$ were measured using Focused Ion Beam (FIB) images and the Heyn intercept method. The average grain size for the $1 \square \mathrm{m}$ thick as-deposited film grown on $\mathrm{SiO}_{2}$ was measured to be $0.75 \square \mathrm{m}$. To study the effect of grain size, the as-deposited film was first tested, annealed in vacuum at $500^{\circ} \mathrm{C}$, and tested again. After annealing, the grain size was measured to be $1.0 \square \mathrm{m}$. For the $\mathrm{Cu}$ films grown on Ta, the average grain size was $0.2 \square \mathrm{m}$ for the $0.5 \square \mathrm{m}$ thick film, $0.4 \square \mathrm{m}$ for the $1.0 \square \mathrm{m}$ thick film, and $0.5 \square \mathrm{m}$ for the $1.7 \square \mathrm{m}$ thick film.

Symmetric x-ray diffraction was used to determine the texture of the films. The results of the scans are shown in Fig 6. The film grown on a $\mathrm{SiO}_{2}$ layer (dash line) shows two peaks, which correspond to the (111) and the (200) reflections. The film grown on Ta (solid line) shows a strong (111) peak, and no observable (200) peaks. 
Table I. - Calculated results for the residual stress on the beam for the $1.0 \square \mathrm{m}$ thick dual textured film.

\begin{tabular}{|c|c|c|}
\hline Cycle & $\begin{array}{c}\text { Residual Film } \\
\text { Stress on Wafer }\end{array}$ & $\begin{array}{c}\text { Calculated Residual Stress in the } \\
\text { Middle of the Film on the Beam }\end{array}$ \\
\hline As-Deposited & $170 \mathrm{MPa}$ & $80 \mathrm{MPa}$ \\
\hline $500^{\circ} \mathrm{C}$ to RT & $260 \mathrm{MPa}$ & $120 \mathrm{MPa}$ \\
\hline
\end{tabular}

Table II. - Calculated results for the residual stress on the beam for the $<111>$ textured films.

\begin{tabular}{|c|c|c|}
\hline Film Thickness & $\begin{array}{c}\text { Residual Film } \\
\text { Stress on Wafer }\end{array}$ & $\begin{array}{c}\text { Calculated Residual Stress in the } \\
\text { Middle of the Film on the Beam }\end{array}$ \\
\hline $0.5 \square \mathrm{m}$ & $169 \mathrm{MPa}$ & $100 \mathrm{MPa}$ \\
\hline $1.0 \square \mathrm{m}$ & $169 \mathrm{MPa}$ & $70 \mathrm{MPa}$ \\
\hline $1.7 \square \mathrm{m}$ & $169 \mathrm{MPa}$ & $40 \mathrm{MPa}$ \\
\hline
\end{tabular}

The residual stress in the dual textured $\mathrm{Cu}$ film was measured using asymmetric X-ray diffraction and the $\sin ^{2} \square$ method (Clemens and Bain, 1992). For the $<111>$ textured $\mathrm{Cu}$ films, the residual stress was measured using the wafer curvature method. These methods, however, give the residual stress in the film where it is supported by the massive substrate. For the bi-layer beam, the relatively thin substrate layer will accommodate some of the misfit strain. The residual stress in the film on the beams can then be calculated using the results from these techniques, and the assumption that the total misfit strain is the same on the beam as on the well-supported regions. Using this assumption, the amount of misfit strain accommodated by the substrate can be determined, and the residual stress in the film on the beams can be calculated. The results of this calculation are shown in Tables I and II. 


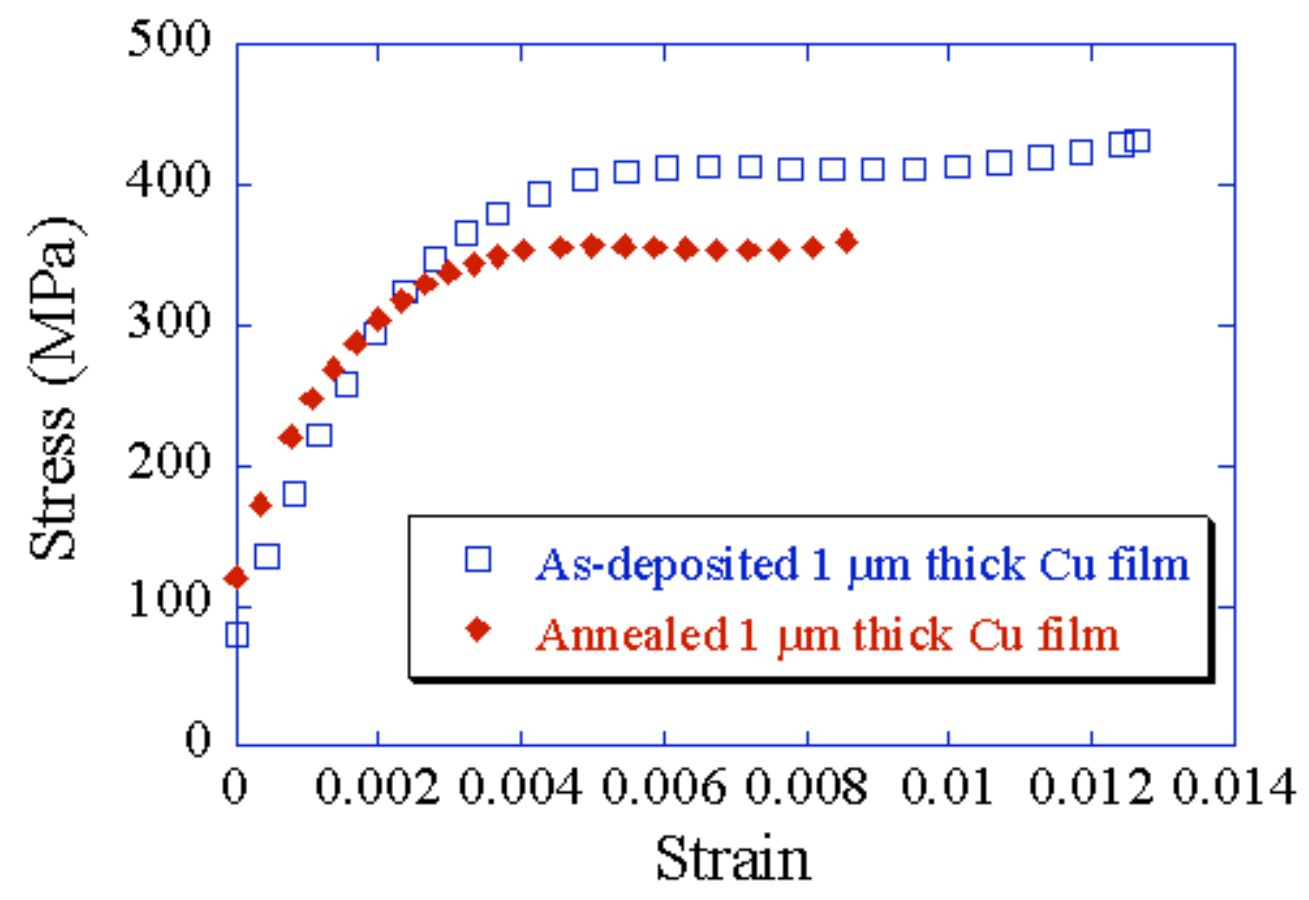

Figure 7 - Stress-strain behavior for an as-deposited and annealed $\mathrm{Cu}$ film.

\section{Results and Discussion}

\subsection{Grain size effect}

Figure 7 shows a plot of the stress-strain behavior determined for both the asdeposited and annealed film with the dual texture. The annealed film has a higher residual tension stress, which is expected since the film deforms plastically during heating, and this deformation causes an increase in the residual tension stress at room temperature. Even though the annealed film was initially in a higher state of biaxial tension, it yielded at a lower stress than the as-deposited film. This behavior is expected since the yield stress is expected to vary inversely with the square root of the grain size.

\subsection{Effect of Texture}

Since $\mathrm{Cu}$ films deposited onto $\mathrm{SiO}_{2}$ are composed of grains with two different orientations, the yielding behavior can be difficult to interpret. We have studied the effect of the dual texture on the yielding of these films using orientation imaging microscopy and a Schmid factor analysis (Florando, 2003). To simplify the situation, it is more 


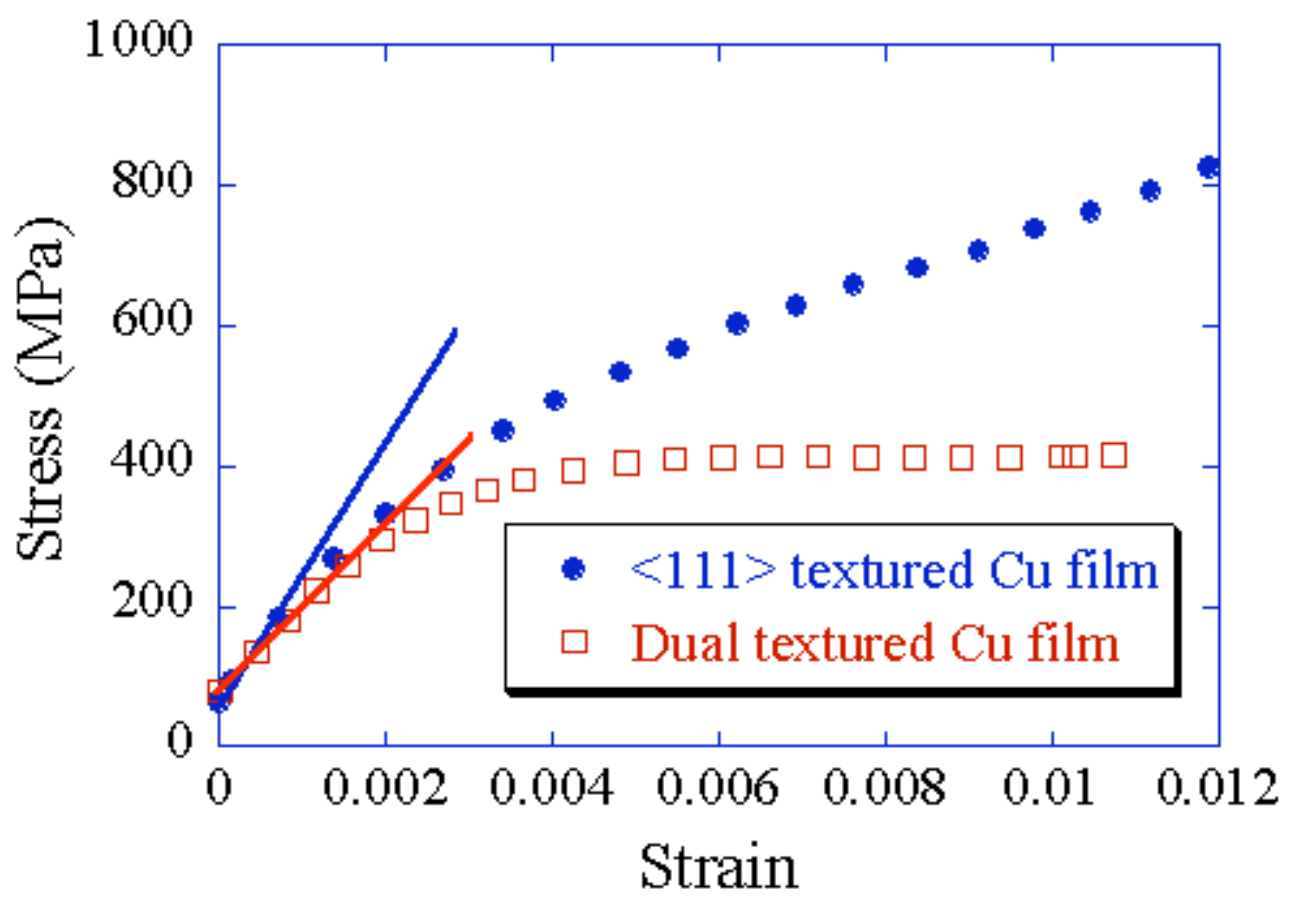

Figure 8 - Stress-strain behavior for a dual texture and $<111>$ textured $1 \square \mathrm{m}$ thick $\mathrm{Cu}$ film.

convenient to study films with a single out-of-plane texture. Vinci (1994) found that sputtering a layer of tantalum at $150^{\circ} \mathrm{C}$, followed by copper deposition at $200^{\circ} \mathrm{C}$, promotes a strong $<111>$ texture. Following that technique, a $1 \square \mathrm{m}<111>$ textured $\mathrm{Cu}$ film was grown. The texture of the film was measured using the x-ray diffraction method, and was confirmed to be strongly $<111>$ textured. The average grain size for this film was measured to be $0.4 \square \mathrm{m}$.

A plot of the stress-strain relations for a $<111>$ textured and the dual textured film is shown in Fig. 8. The $<111>$ textured film has a higher elastic slope, which is expected since the plane strain modulus is largest in the $<111>$ plane. The $<111>$ textured film also shows a much higher rate of hardening, a hardening slope of nearly $E / 4$, while the highest hardening slope for the dual texture film is about E/14. It should be noted that these strain hardening rates are much higher than those seen in bulk $\mathrm{Cu}$. Based on the work of Jain et al. (1990) and Freund (1994), we have suggested a dislocation model to account for the high strain hardening rates in thin films. The model is based on the stress required to move a threading dislocation past the stress fields of an array of parallel and intersecting "misfit" dislocations. The results of the model show very high rates of strain 


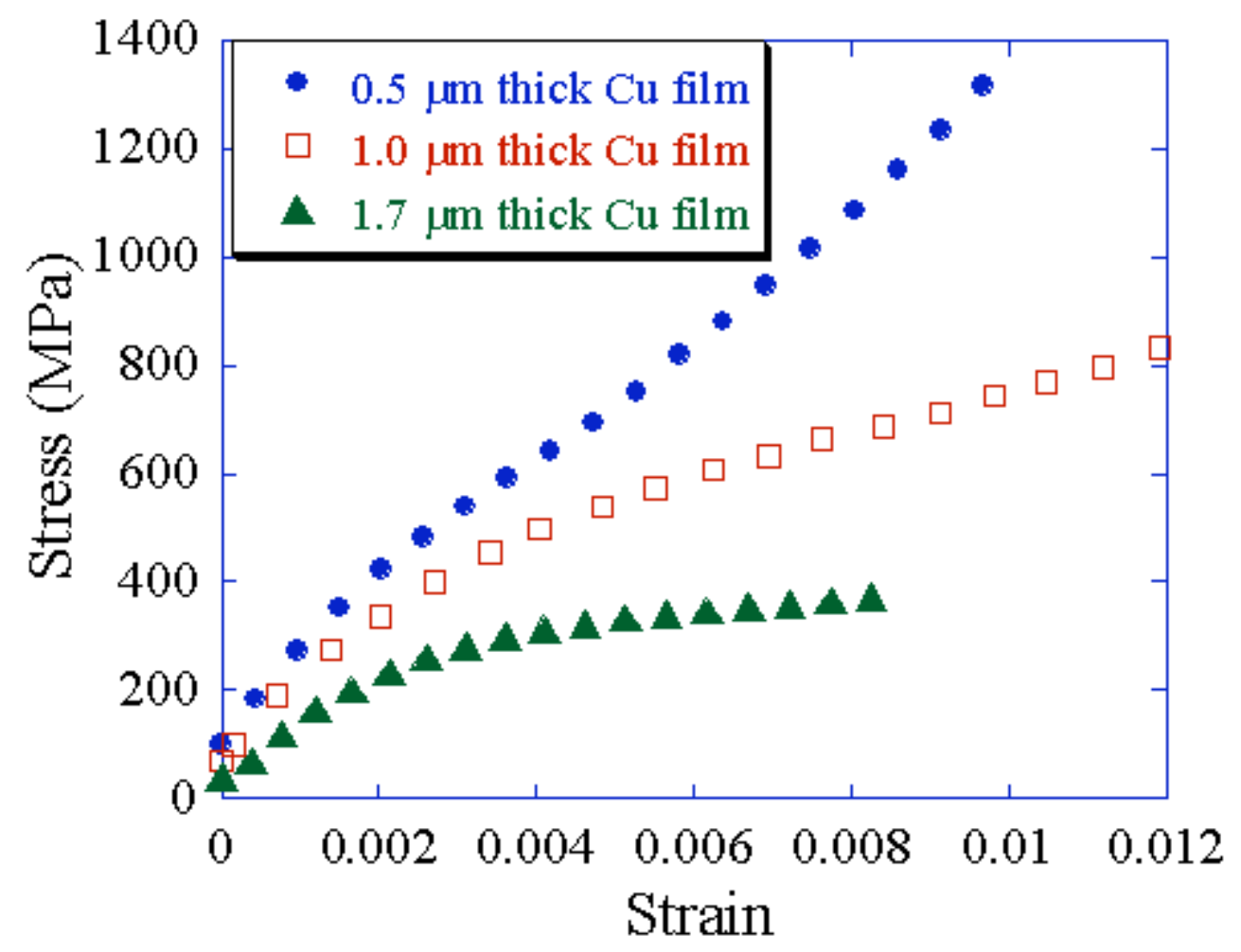

Figure 9 - Stress-strain behavior for $<111>$ textured $\mathrm{Cu}$ films of three different film thickness.

hardening rates, on the order of the $\mathrm{E} / 2$. The higher hardening rates in the $<111>$ textured film may be attributed to the smaller grain size, as suggested by Hommel et al. (2001), or it could be evidence that there is a difference in the strain hardening mechanism between $<111>$ and $<100>$ grains. Hommel et al. (2001), using an x-ray tensile testing method, also found that the $<111>$ grains strain harden at a rate nearly twice that of the $\langle 100\rangle$ grains, even for the same nominal grain size. They could not however, find a suitable dislocation theory to explain the phenomenon.

\subsection{Effect of Film Thickness}

To study the effect of film thickness, two additional $\mathrm{Cu}$ films with strong $<111>$ texture, in addition to the $1.0 \square \mathrm{m}$ film, were deposited. The two additional films have a thickness of $0.5 \square \mathrm{m}$, and $1.7 \square \mathrm{m}$. Fig. 9 shows the stress-strain behavior for the three film thicknesses. It should be noted that these stress-strain curves are reproducible, and the data shown here are representative of the samples. 
Since the texture should be similar for all three films, the elastic loading slope should be equal. The slope for the $1.7 \square \mathrm{m}$ thick film is a little lower than for the other two films, but the difference is within the range of experimental variation. The yield stress for the three films is different, with the thinnest film having the highest yield stress. This result is expected as Freund (1987) and Nix (1989) have shown that the yield stress is inversely related to the film thickness. The grain size measurements for the three films shows that the thinnest film has the smallest average grain size. Since the smaller grain size can also contribute to the increase in the flow stress, is it difficult to separate the effect of film thickness and grain size in these experiments.

The most striking feature in Fig. 9, however, is the large difference in the work hardening rates between the three films. The $1.7 \square \mathrm{m}$ thick film has a linear strainhardening rate of about $\mathrm{E} / 9$, while the $1.0 \square \mathrm{m}$ film has a hardening rate of $\mathrm{E} / 4$. The 0.5 $\square \mathrm{m}$ thick film has an initial hardening rate for $\mathrm{E} / 2.2$, but the slope increases to a hardening slope of E/1.3 at a strain of about 0.006 . The systematic increase in the strain hardening rates for decreasing film thickness, as well as the bi-linear strain hardening behavior seen in the $0.5 \square \mathrm{m}$ thick film, has been predicted by Nicola, Van der Giessen, and Needleman (2003) using a 2-D plane strain dislocation simulation. In their simulation, dislocations pile up near the film-substrate interface, which forms a boundary layer that has a much higher dislocation density and in-plane stress than the rest of the film. This boundary layer acts as an obstacle for other dislocations to move past, and the size of the boundary layer is independent of film thickness. Therefore, the thinner the film, the larger the effect of the boundary layer. This type of argument leads to an increase in the strain hardening rates for decreasing film thickness. For films that are sufficiently thin, as the film yields and more dislocations pile up at the interface, there develops a large enough back-stress to prevent the nucleation of new mobile dislocations. This effect leads to a secondary hardening effect, and an increase in the slope of strain hardening rate, or bi-linear strain hardening, similar to the effect seen in our thinnest textured copper films. 


\section{Conclusions}

A triangular microbeam bending technique for the testing of thin metal films on elastic substrate has been developed. We show that Ramberg-Osgood parameters describing plastic deformation of the film can be determined from an analysis of the experimental load-displacement data. The analysis also provides a good estimate of the position of the neutral plane for bending and this, in turn, permits a determination of the average stress-strain relation for the film without constraining the film to follow the Ramberg-Osgood law. This beam bending technique has been used to study the effect of microstructure on the stress-strain properties of $\mathrm{Cu}$ films. The results show that the yield stress increases with decreasing grain size, and decreasing film thickness, as expected. The strain hardening rates for the $<111>$ textured film were found to be considerably higher than for the dual textured film with the same film thickness. This difference suggests that there might be a difference in strain hardening mechanisms between the $<111>$ and $<100>$ grains. Finally, the strain hardening rate for $<111>$ textured films was found to be extremely high, and the rates seem to correlate with the film thickness, with the thinnest films having the highest strain hardening rates. The $0.5 \square \mathrm{m}$ film also exhibited a bi-linear strain hardening behavior. This result, as well as the systematic increase in the strain hardening rate with decreasing film thickness, has been predicted by 2-D dislocation simulations.

\section{Acknowledgments}

The authors are grateful to Prof. L.B. Freund of Brown University for his constructive criticism of an early version of this paper. The authors would also like to thank the Intel Graduate Fellowship Program and the Department of Energy (DE-FG03-89ER45387) for funding this project. Special thanks goes to Qing Ma, Harry Fujimoto, and the R1 staff in Components Research at Intel Corp. for help in processing of the wafers, to Oliver Kraft and Ruth Schwaiger formerly at the Max-Planck-Institut für Metallforschung in Stuttgart, Germany for their useful discussion and FIB pictures, to Bryan Tracy and Jonnie Barragan from Advanced Micro Devices (AMD) for the use of their FIB machine and for funding the Orientation Imagining Microscopy work, and to Michael Uchic from the 
Wright-Patterson Air Force Base for taking FIB pictures of our films. This work made use of the National Nanofabrication Users Network facilities funded by the National Science Foundation under award number ECS-9731294. This work was also performed under the auspices of the U.S. Department of Energy by University of California, Lawrence Livermore National Laboratory under Contract W-7405-Eng-48.

\section{Appendix A. Elastic-Plastic Bending Analysis}

Consider a small element in a bi-layer beam subjected to an incremental bending moment (per unit width) $\left[M=\left(L / w_{O}\right)[P\right.$. This bending moment produces an

incremental curvature in the beam $\square=\left(2 / L^{2}\right) L u$. To determine the relation between the incremental loads and displacements, for comparison with experiment, we first seek the relation between the incremental moment, $\Pi M$, and the incremental curvature, $\Pi$ for such a bi-layer beam. Hereafter it is understood that incremental quantities or timeindependent derivatives are always being computed, for comparison with the experimental load-displacement data, so the term "incremental" is often dropped to simplify the text.

For a beam in bending, as shown in Fig. A.1, the curvature can be related to the strains in the beam according to

$$
\prod_{x x}(y)=\square\left(y \square y_{o}\right)
$$

where $y_{o}$ is the position of the neutral plane for bending and where, for convenience, we choose downward curvature to be positive, unlike the usual sign convention.

Knowing the strains permits a direct calculation of the stresses, provided the constitutive laws for the film and substrate are known. When the film and substrate are deforming elastically, the stresses in the substrate and film are given by

$$
\square_{x x}^{s}=B_{s} D_{x x}^{s}
$$

and 


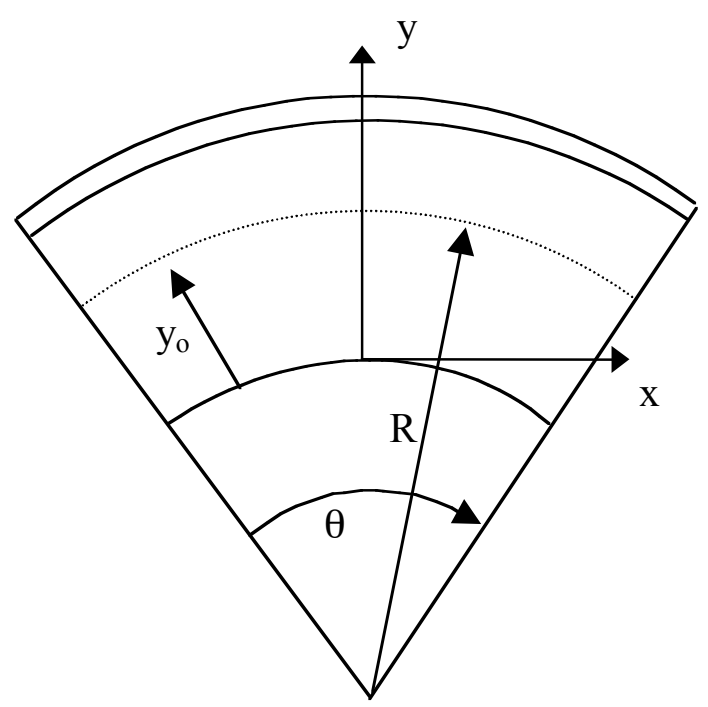

Figure A.1 - The bending of a bi-layer beam

$$
\square_{x x}^{f}=B_{f} \square_{x x}^{f}
$$

where $B_{S}$ and $B_{f}$ are the plane strain moduli for the substrate and film, respectively. We assume that the substrate always behaves in a linear elastic manner. Initially, the film also strains elastically, but then begins to deform plastically. For the present analysis we assume that the deformation properties of the film can be modeled using the empirical Ramberg-Osgood stress-strain law

$$
\square^{f}=\square_{e}^{f}+\square_{p}^{f}=\frac{\square^{f}}{E_{f}}+\frac{\square_{o}}{E_{f}} \frac{\square \square^{f}}{\square \square_{o}} \square^{m},
$$

where $\square^{f}$ is the equivalent strain, consisting of an elastic part, $\square_{b}^{f}$, and a plastic part, $\square_{p}^{f}$. Also $\square^{f}$ is the equivalent stress, $E_{f}$ is Young's modulus, $\square_{o}$ is the yield stress, and $\mathrm{I} / \mathrm{m}$ is a strain hardening exponent, all pertaining to the film. In addition, we assume that the film is subjected to plane strain deformation, $\square_{z z}^{f}=0, \square_{y y}^{f}=0$, such that both $\square_{x x}^{f}$ and $\square_{z z}^{f}$ develop during the course of bending. For such plane strain deformation the 
total strains may be calculated from their elastic (e) and plastic (p) components as follows:

$$
\begin{aligned}
& \square_{x x}^{f}=\square_{x x}^{f, e}+\square_{x x}^{f, p} \\
& \square_{z z}^{f}=\square_{z z}^{f, e}+\square_{z z}^{f, p}=0 . \\
& \square^{f}=\square_{e}^{f}+\square_{p}^{f}
\end{aligned}
$$

We also assume that the Levy-Mises flow law can be used to describe plastic deformation in the film:

$$
\begin{aligned}
\square_{x x}^{f, p} & =\frac{\square_{x x}^{f} \square \frac{1}{2} \square_{z z}^{f}}{\square^{f}} \Gamma_{p}^{f} \\
\square_{z z}^{f, p} & =\frac{\square_{z z}^{f} \square \frac{1}{2} \square_{x x}^{f}}{\square^{f}} \Gamma_{p}^{f}
\end{aligned}
$$

where the equivalent stress $\Pi^{f}$ is expressed as

$$
\square^{f}=\sqrt{\frac{1}{2} \square_{x x}^{f^{2}}+\square_{z z}^{f^{2}}+\left(\square_{x x}^{f} \square \square_{z z}^{f}\right)^{2} \square} .
$$

Finally, we use Hooke's law to describe the relation between the elastic strains and the stresses

$$
\begin{aligned}
& \square_{x x}^{f, e}=\frac{1}{E_{f}}\left(\square_{x x}^{f} \square \square_{f} \square_{z z}^{f}\right) \\
& \square_{z z}^{f, e}=\frac{1}{E_{f}}\left(\square_{z z}^{f} \square \square_{f} \square_{x x}^{f}\right)
\end{aligned} .
$$

Using Hooke's law and the Levy-Mises flow law, together eqn. (A.5), leads directly to 


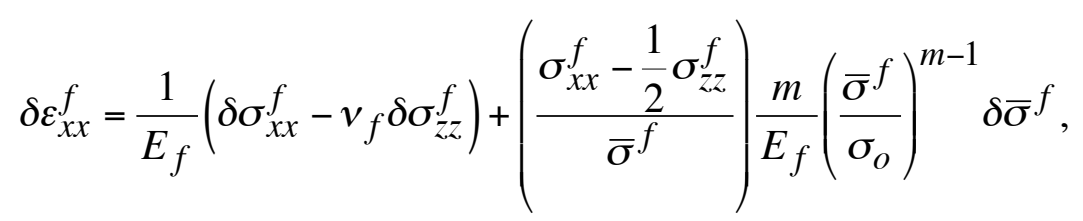

and

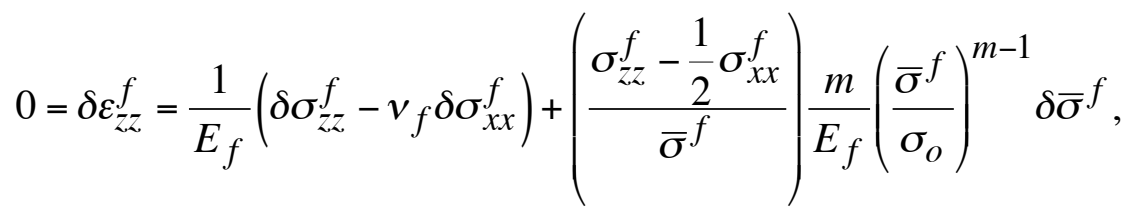

where the equivalent stress, eqn.(A.7), can be written as

$$
\square^{f}=\frac{1}{2 \square^{f}}\left[\left(2 \square_{x x}^{f} \square \square_{z z}^{f}\right) \square_{x x}^{f}+\left(2 \square_{z z}^{f} \square \square_{x x}^{f}\right) \square_{z z}^{f}\right] .
$$

Combining eqns.(A.9) and (A.10), leads to

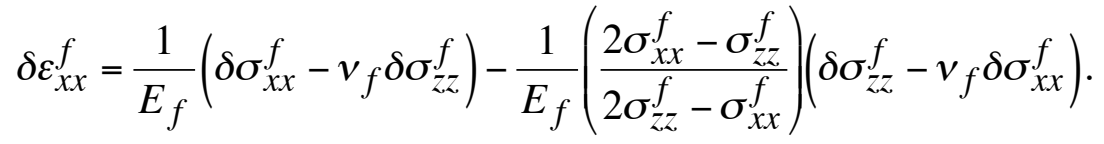

As described below, the total strain increment $\square_{x x}$ is directly related to the load point deflection, through the curvature, $\square=\left(2 / L^{2}\right) \square u$, while the stress increment $\square_{x x}^{f}$ is directly related to the measured load increment, through the moment, $\square M=\left(L / w_{O}\right) \square P$. By contrast, the stress increment $\prod_{z z}^{f}$, which appears in eqn.(A.12) is not directly measurable and must be calculated using eqn.(A.10). Solving eqn.(A.10) for $\square_{z z}^{f}$ leads to

$$
\square_{z z}^{f}=K_{2} \square_{x x}^{f},
$$

where 


$$
K_{2}=\frac{\left(\square_{f} \square^{f} \square K_{1}\left(2 \square_{x x}^{f} \square \square_{z z}^{f}\right)\right)}{\left(\square^{f}+K_{1}\left(2 \square_{z z}^{f} \square \square_{x x}^{f}\right)\right)}
$$

and

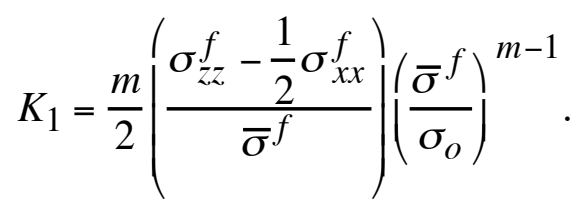

Combining eqns.(A.13) and (A.12) leads to

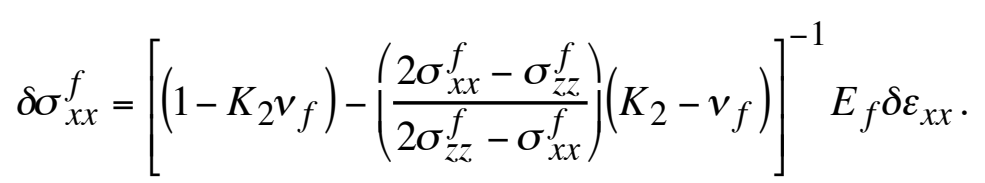

Using eqns.(A.16) and (A.13). the stress increments, $\square_{x x}^{f}$ and $\square_{z z}^{f}$, can be computed for each strain increment, $\square_{x x}$, updating the stresses and other quantities in these relations after each increment.

We now turn to the computation of the incremental moment and curvature during the course of bending. The incremental moment (per unit width) can be computed as

$$
\square M=\square_{u b s t r a t e} \prod_{x x}^{s}\left(y \square y_{o}\right) d y+\square_{i l m} \prod_{x x}^{f}\left(y \square y_{o}\right) d y,
$$

where $y_{o}$ is the position of the neutral plane for bending. Using eqns.(A.1), (A.2) and (A.16) this leads to

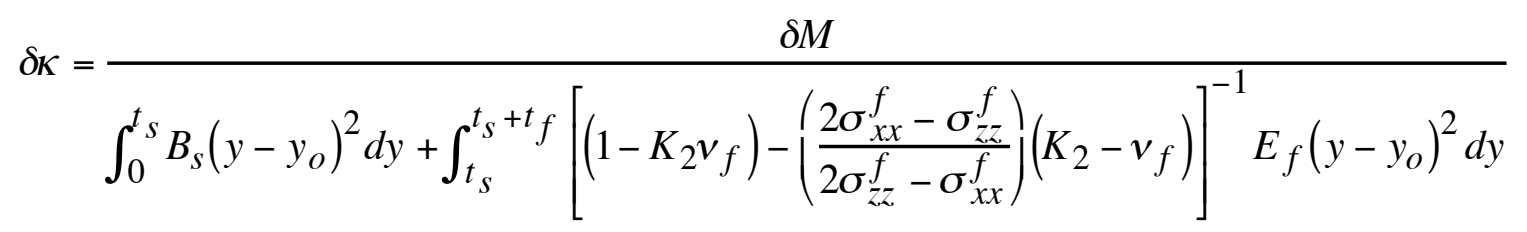

(A.18). 
Using $\square M=\left(L / w_{o}\right) \square P$ and $\square=\left(2 / L^{2}\right) \square u$ with eqn.(A.18) we find an expression for the load increment corresponding to each load point displacement

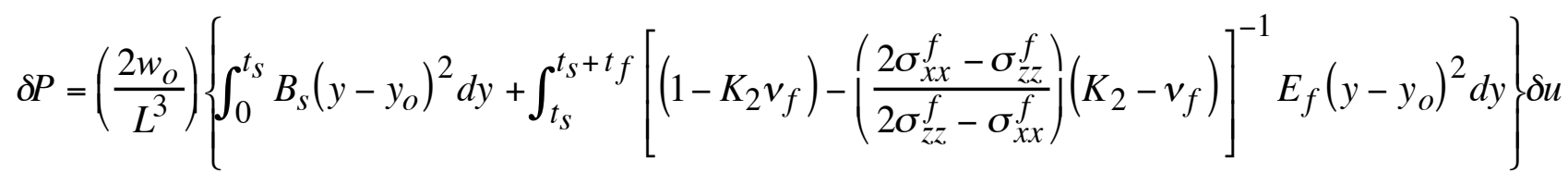

This equation permits the incremental loads for a bi-layer beam to be calculated by knowing the incremental displacements, assuming a Ramberg-Osgood stress-strain law for the film. Utilizing eqn.(A.19), a theoretical load-displacement curve can be calculated for a film that follows the Ramberg-Osgood law. By changing the yield stress $\square_{o}$, and the strain hardening exponent $1 / \mathrm{m}$, the theoretical load-displacement curve can be fitted to match the experimental data.

To implement eqn.(A.19) numerically, for comparison with the experimental loaddisplacement data, the position of the neutral plane for bending, $y_{o}$, must be known at each point in the bending process. Before yielding has occurred, the position of the neutral plane is fixed and can be found by solving

$$
0=\square M=\bigsqcup^{s} B_{s}\left(y \square y_{o}\right) d y+\square^{s}{ }^{+t f} B_{f}\left(y \square y_{o}\right) d y .
$$

This calculation may be understood by thinking of a virtual uniform extensional strain that produces no change of curvature and thus no bending moment about the neutral plane. After the film starts to deform plastically, the position of the neutral plane changes, because the capacity of the film to support stresses does not rise in proportion to the bending and, thus, must be computed after each loading increment. Again the position of the neutral plane for bending can be found by noting that a virtual extensional strain at any point in the bending process causes no change in curvature and thus no change in moment about the neutral plane. Thus the neutral plane for bending, $y_{o}$, can be found by solving the following equation: 


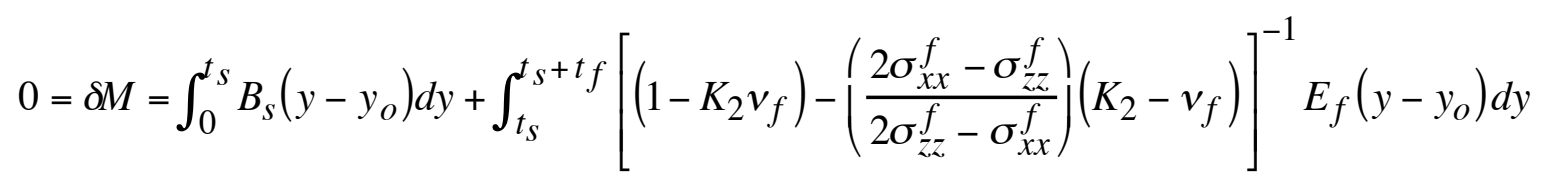
(A.21)

Equation (A.19) can then be used to model the experimental load-displacement data, assuming a Ramberg-Osgood stress-strain law for the film, using eqn.(A.21) to compute the neutral plane for bending after each increment.

\section{References}

Baker, S. P. and Nix, W. D., 1994. Mechanical-Properties of Compositionally Modulated Au-Ni Thin-Films : Nanoindentation and Microcantilever Deflection Experiments. Journal of Materials Research 9(12): 3131-3145.

Clemens, B. M. and Bain, J. A., 1992. Stress Determination in Textured Thin-Films Using X-Ray-Diffraction. Mrs Bulletin 17(7): 46-51.

DiLella, D., Whitman, L. J., Colton, R. J., Kenny, T. W., Kaiser, W. J., Vote, E. C., Podosek, J. A. and Miller, L. M., 2000. A micromachined magnetic-field sensor based on an electron tunneling displacement transducer. Sensors and Actuators APhysical 86(1-2): 8-20.

Florando, J., Fujimoto, H., Ma, Q., Kraft, O., Schwaiger, R. and Nix, W. D., 1999. Measurement of thin film mechanical properties by microbeam bending. Materials Reliability in Microelectronics IX., Warrendale, PA, Mater. Res. Soc. Symp. Proc.

Florando, J. N., 2003. Measurement of the Mechanical Properties of Copper Thin Films by Microbeam Bending. Ph.D. Dissertation, Stanford University. 
Freund, L. B., 1987. The Stability of a Dislocation Threading a Strained Layer On a Substrate. Journal of Applied Mechanics-Transactions of the Asme 54(3): 553557.

Freund, L.B., 1994. The Mechanics of Dislocations in Strained-Layer SemiconductorMaterials, Advances in Applied Mechanics 30: 1-66.

Garcia, E. J. and Sniegowski, J. J., 1995. Surface Micromachined Microengine. Sensors and Actuators A-Physical 48(3): 203-214.

Holhlfelder, R. J., 1998. Bulge and Blister Testing of Thin Films and Their Interfaces. Ph.D. Dissertation, Stanford University.

Hommel, M. and Kraft, O., 2001. Deformation behavior of thin copper films on deformable substrates. Acta Materialia 49(19): 3935-3947.

Jain, S.C., Willis, J.R. and Bullough, R, 1990. A review of theoretical and experimental work on the wtructure of $\mathrm{Ge}_{\mathrm{x}} \mathrm{Si}_{1-\mathrm{x}}$ strained layers and superlattices, with extensive bibliography. Advances in Physics, 39(2): 127-190.

Nicola, L., Van der Giessen, E. and Needleman, A., 2003. Discrete Dislocation Analysis of Size Effects in Thin Films. J. Applied Phys. 93: 5920-5928.

Nix, W. D., 1989. Mechanical-Properties of Thin-Films. Metallurgical Transactions APhysical Metallurgy and Materials Science 20(11): 2217-2245.

Spearing, S. M., 2000. Materials issues in microelectromechanical systems (MEMS). Acta Materialia 48(1): 179-196.

Vinci, R. P., 1994. Thermal Strains and Stresses in Copper Thin Films and Microelectronic Interconnect Structures. Ph.D. Dissertation, Stanford University. 
Weihs, T. P., Hong, S., Bravman, J. C. and Nix, W. D., 1988. Mechanical Deflection of Cantilever Microbeams : a New Technique For Testing the Mechanical-Properties of Thin-Films. Journal of Materials Research 3(5): 931-942. 